\title{
HUBUNGAN ANTARA KB SUNTIK 3 BULAN PADA AKSEPTOR KB $\geq 3$ KALI SUNTIK DAN METRORAGIA TERHADAP PENINGKATAN BERAT BADAN
}

\section{Intan Sari}

Akademi Kebidanan Budi Mulia Prabumulih

\section{Informasi Artikel :}

Diterima : $\quad$ Maret 2019

Disetujui : Juni 2019

"Korespondensi Penulis :

Intannnadhifa215@gmail.com

\begin{abstract}
A B S T R A K
Di Indonesia, Kontrasepsi hormonal jenis KB Suntik semakin banyak dipakai hal ini dikarenakan metode KB yang paling banyak diketahui masyarakat, cara kerja yang efektif, praktis dan biaya yang dikeluarkan relatif murah dan aman Penelitian ini bertujuan untuk mengetahui hubungan antara KB Suntik 3 Bulan Pada Akseptor KB $\geq .3$ kali suntik dan Metroragia Terhadap Peningkatan Berat Badan Jenis penelitian ini menggunakan metode Survei Analitik dengan pendekatan Cross Sectional. Populasi penelitian ini adalah semua akseptor KB suntik 3 bulan yang datang ke Puskesmas Tanjung Raman Kota Prabumulih Tahun 2019. Sampel penelitian ini diambil secara non random tehnik Accidental Sampling yaitu semua ibu-ibu yang ikut KB Suntik 3 bulan yang datang saat dilakukan penelitian di Puskesmas Tanjung Raman Kota Prabumulih Tahun 2019. Tehnik pengumpulan data pada penelitian ini dengan menggunakan data primer yaitu data yang diperoleh dari wawancara langsung berstruktur dengan menggunakan data pertanyaan berupa kuesioner. Alat pengumpulan data berupa kuesioner. Pada penelitian ini analisis data diuji dengan menggunakan uji statistik chi-Square dengan tingkat kemaknaan $\alpha=0,05$ menggunakan komputerisasi. Dari Hasil penelitian menunjukan bahwa ada hubungan yang bermakna antara peningkatan berat badan dengan pemakaian KB suntik 3 bulan dimana $p$ value $=0,009$. Ada hubungan yang bermakna antara metroragia dengan akseptor KB suntik 3 bulan $\geq 3$ kali dimana $p$ value $=0,016$ lebih kecil dari $\alpha 0,05$
\end{abstract}

Kata Kunci : KB Suntik 3 bulan, Peningkatan Berat Badan, Metroragia

\begin{abstract}
In Indonesia, KB type hormonal contraception is increasingly being bought because the family planning method is most widely known to the public, effective, practical work methods and the costs are relatively cheap and safe $\geq 3$ times injections and Metroragia Against Increased Body Weight This type of research uses the Analytical Survey method using Cross Sectional. The population of this study were all injectable family planning acceptors 3 months who came to the Tanjung Raman Health Center in Prabumulih City in 2019. The study sample was taken from the random non-technical technique of Prabumulih City in 2019. The technique of collecting data in this study using primary data is data obtained from direct interview structured using question data in the form of a questionnaire. Data tools consist of questionnaires. In this study publication data analysis using chi-square statistical test with a significance level of $\alpha=0.05$ using computerization. From the results of the study showed that there was a significant relationship between the increase in body weight with the use of 3-month injection KB where $p$ value $=0.009$. There was a significant relationship between metroragia and 3 month injection KB acceptors $\geq 3$ times where $p$ value $=0.016$ was smaller than $\alpha 0.05$
\end{abstract}

Keywords: 3-month injection KB, weight gain, Metroragia 


\section{PENDAHULUAN}

Di Indonesia, Kontrasepsi hormonal jenis KB Suntik semakin banyak dipakai hal ini dikarenakan metode $\mathrm{KB}$ yang paling banyak diketahui masyarakat, cara kerja yang efektif, praktis dan biaya yang dikeluarkan relatif murah dan aman. Penggunaan kontrasepsi di Indonesia di atas persentase rata-rata negara-negara ASEAN, TFR dibawah TFR rata-rata ASEAN dan unmeet need berada di pertengahan (urutan 4 dari 7 negara) (Kemenkes RI, 2013).

Data SDKI 2012 menunjukkan tren Prevalensi Penggunaan Kontrasepsi atau Contraceptive Prevalence Rate (CPR) di Indonesia sejak 1991 - 2012 cenderung meningkat, sementara tren Angka Fertilitas atau Total Fertility Rate (TFR) cenderung menurun. Tren ini menggambarkan bahwa meningkatnya cakupan wanita usia 15-49 tahun yang melakukan $\mathrm{KB}$ sejalan dengan menurunnya angka fertilitas nasional. Bila dibandingkan dengan target RPJMN 2014, CPR telah melampaui target $(60,1 \%)$ dengan capaian $61,9 \%$ namun TFR belum mencapai target $(2,36)$ dengan angka tahun 2012 sebesar 2,6 (BKKBN,2014).

Akseptor KB di Sumatera Selatan terus mengalami peningkatan, tercatat sebanyak 275.289 akseptor baru. Hal ini dikarenakan semakin tingginya kesadaran masyarakat Sumatera Selatan untuk membatasi kelahiran. Pada tahun 2018 ini, tercatat 976.600 merupakan peserta KB Aktif. Sebagian peserta merupakan akseptor KB suntik sebanyak 459.361 (Kompas.com, 2018).

Berdasarkan laporan Pengendalian Lapangan tercatat data akseptor KB aktif di kota Prabumulih Tahun 2016 sebesar 22.243 atau 92,95\% dari Pasangan Usia Subur (PUS) yang menjadi sasaran sebesar 23.928. Akseptor KB Suntik sebanyak 14.298 atau 59,75\% terhadap PUS, akseptor kontrasepsi pil 1.742 atau 7,28\%, akseptor implant 3.564 atau $14,89 \%$, akseptor AKDR 2.026 atau 8,46\%, akseptor kondom 237 atau $0,99 \%$, akseptor MOW 273 atau $1,14 \%$ dan akseptor MOP 103 atau 0,43\%. Pencapaian terendah yaitu MOP hanya $0,43 \%$ sedangkan pencapaian tertinggi yaitu kontrasepsi suntik sebesar 59,75\% (BKKBN Kota Prabumulih, 2016).

Mekanisme kerja komponen progesteron atau derivat testosteron adalah dengan menghalangi pengeluran FSH dan LH sehingga tidak terjadi pelepasan ovum, mengentalkan lendir serviks, sehingga sulit ditembus spermatozoa, mengganggu peristaltik tuba fallopi, sehingga konsepsi dihambat, mengubah suasana endometrium, sehingga tidak sempurna untuk implantasi hasil konsepsi. (Manuaba, dkk.2010)

Setiap perempuan memiliki reaksi berbeda terhadap kontrasepsi hormonal. Bagi akseptor KB suntik progestin, kenaikan berat badan bisa saja terjadi. Berat badan bertambah sekitar 1-2 kg per tahun selama menjadi akseptor kb suntik, tetapi kenaikan tersebut dapat juga merupakan berat normal seiring dengan bertambahnya usia. Jika ada wanita yang mengalami kenaikan berat badan saat menggunakan alat kontrasepsi hormonal, ada kemungkinan hal tersebut disebabkan oleh faktor internal dan eksternal. Faktor internal dapat berupa riwayat obesitas dari keluarga, sementara eksternal bisa disebabkan oleh kandungan hormon pada alat kontrasepsi.(Adhiyasasti, 2018).

Penggunaan kontrasepsi hormonal dengan kadar estrogen yang tinggi dapat menyebabkan pengendapan lemak pada jaringan tubuh. Sementara itu, hormon progesteron dapat merangsang pusat pengendali nafsu makan di hipotalamus yang menyebabkan akseptor makan lebih banyak dari biasanya. Progesteron mempermudah penumpukkan karbohidrat dan gula menjadi lemak.( Adhiyasasti, 2018).

Perubahan pada pola haid ini terjadi karena pengaruh hormon progesteron di mulai dari perdarahan bercak atau flek hingga perdarahan yang berkepanjangan, bahkan $70 \%$ pengguna $\mathrm{KB}$ suntik bisa tidak mens. Dan setiap individu memiliki respon yang berbeda-beda dalam penerimaan hormone ini (Haryanto, 2011).

Disamping memiliki efek samping kenaikan berat badan, kontrasepsi suntik suntik juga memiliki efek samping seperti amenorea (40 persen), spoting (bercak darah) dan menoragia. Secara umum semua gangguan haid disebabkan karena adanya ketidakseimbangan hormon sehingga endometrium mengalami perubahan.

Berdasarkan permasalahan dari latar belakang yang telah dikemukakan diatas, maka peneliti tertarik untuk melakukan penelitian mengenai :"Apakah ada hubungan antara KB suntik 3 bulan pada akseptor KB $\geq 3$ Kali Suntik dan metroragia terhadap peningkatan berat badan ? 


\section{METODE PENELITIAN}

Desain pada penelitian ini adalah upaya memahami dan memecahkan masalah secara ilmiah, sistematis dan logis.(Notoatmodjo,2010). Jenis penelitian ini menggunakan metode Survei Analitik dengan pendekatan Cross Sectional yaitu suatu penelitian uyang sama variabelnya, baik variabel independen maupn variabel dependen diobservasi atau dikumpulkan sekaligus dalam waktu yang bersamaan. Populasi penelitian ini adalah semua akseptor KB suntik 3 bulan yang datang ke Puskesmas Tanjung Raman Kota Prabumulih Tahun 2019. Sampel penelitian ini diambil secara non random tehnik Accidental Sampling yaitu semua ibu-ibu yang ikut KB Suntik 3 bulan yang datang saat dilakukan penelitian di Puskesmas Tanjung Raman Kota Prabumulih Tahun 2019. Tehnik pengumpulan data pada penelitian ini dengan menggunakan data primer yaitu data yang diperoleh dari wawancara langsung berstruktur dengan menggunakan data pertanyaan berupa kuesioner.

Pada penelitian ini analisis data diuji dengan menggunakan uji statistik chi-Square dengan tingkat kemaknaan $\alpha=0,05$ menggunakan komputerisasi..

\section{HASIL PENELITIAN}

Tabel 1. Distribusi Frekuensi Akseptor Berdasarkan Peningkatan Berat Badan

\begin{tabular}{cccc}
\hline No & $\begin{array}{c}\text { Peningkatan } \\
\text { Berat Badan }\end{array}$ & Frekuensi & $\begin{array}{c}\text { Prosentase } \\
(\mathbf{\%})\end{array}$ \\
\hline 1 & Naik & 20 & $66,7 \%$ \\
2 & Tidak Naik & 10 & $33,3 \%$ \\
\hline & Jumlah & 30 & $100 \%$ \\
\hline
\end{tabular}

Pada tabel 1 menunjukkan akseptor yang mengalami peningkatan berat badan yaitu 20 responden $(66,7 \%)$ sedangkan yang tidak mengalami peningkatan berat badan yaitu 10 responden $(33,3 \%)$.

Tabel 2. Distribusi Frekuensi Akseptor Berdasarkan Metroragia

\begin{tabular}{|c|c|c|c|}
\hline No & Metroragia & Frekuensi & Prosentase (\%) \\
\hline 1 & Tidak & 11 & $36,7 \%$ \\
\hline 2 & Ya & 19 & $66,3 \%$ \\
\hline & Jumlah & 30 & $100 \%$ \\
\hline
\end{tabular}

yang mengalami metroragia sebanyak 19 responden $(66,3 \%)$.

Tabel 3 Distribusi Akseptor berdasarkan Penggunaan Kontrasepsi KB Suntik 3 Bulan Sekali yang $\geq 3$ kali.

\begin{tabular}{llcc}
\hline No & $\begin{array}{c}\text { Pengguna } \\
\text { Kontrasepsi KB } \\
\text { Suntik 3 Bulan } \\
\text { yang } \geq 3 \text { kali }\end{array}$ & Frekuensi & $\begin{array}{c}\text { Prosentase } \\
(\%)\end{array}$ \\
\hline 1 & Ya & 24 & $80,0 \%$ \\
\hline 2 & Tidak & 6 & $20,0 \%$ \\
\hline & Jumlah & 30 & $100 \%$ \\
\hline
\end{tabular}

Pada Tabel 4 menunjukkan akseptor KB Suntik 3 bulan yang $\geq 3$ kali yaitu 24 responden $(80,0 \%)$, sedangkan akseptor $\mathrm{KB}$ Suntik 3 bulan yang < 3 kali yaitu 6 responden $(20,0 \%)$.

Tabel 4. Hubungan antara Peningkatan Berat Badan dengan Penggunaan Kontrasepsi KB Suntik 3 bulan $\geq 3$ kali suntik

\begin{tabular}{|c|c|c|c|c|c|c|c|c|}
\hline \multirow{3}{*}{$\begin{array}{l}\mathbf{N} \\
\mathbf{0}\end{array}$} & \multirow{3}{*}{$\begin{array}{l}\text { Peningka } \\
\text { tan Berat } \\
\text { Badan }\end{array}$} & \multicolumn{4}{|c|}{$\begin{array}{c}\text { Pengguna KB suntik } \\
3 \text { bulan } \geq 3 \text { kali }\end{array}$} & \multirow{3}{*}{$\begin{array}{c}\text { Jumlah } \\
n\end{array}$} & \multicolumn{2}{|c|}{ Kemaknaan } \\
\hline & & \multicolumn{2}{|c|}{$\mathbf{Y a}$} & \multicolumn{2}{|c|}{ Tidak } & & & \\
\hline & & $\mathbf{n}$ & $\%$ & $\mathbf{n}$ & $\%$ & & $\%$ & \\
\hline 1 & Naik & 19 & 95,0 & 1 & 5,0 & 20 & 100 & $\mathrm{p}$ value \\
\hline \multirow[t]{2}{*}{2} & Tidak & 5 & 50,0 & 5 & 50,0 & 10 & 100 & 0,009 \\
\hline & Jumlah & 24 & & 6 & & 30 & 100 & $\begin{array}{c}\text { Bermak } \\
\text { na }\end{array}$ \\
\hline
\end{tabular}

Dari tabel di atas, dapat dilihat bahwa Akseptor yang menggunakan $\mathrm{KB}$ suntik 3 bulan $\geq 3$ kali peningkatan berat badannya naik lebih besar $(95,0 \%)$ di bandingkan dengan akseptor yang tidak menggunakan KB suntik 3 bulan $\geq 3$ kali (5,0\%).

Hasil pengujian uji statistic dengan menggunakan Chi-Square menunjukan bahwa ada hubungan yang bermakna antara peningkatan berat badan dengan pemakaian KB suntik 3 bulan dimana $p$ value $=0,009$ lebih kecil dari $\alpha 0,05$ sehingga hipotesis yang menyatakan ada hubungan antara peningkatan berat badan dengan pemakaian KB suntik 3 bulan terbukti.

Tabel 5. Hubungan antara Metroragia dengan Penggunaan Kontrasepsi KB Suntik 3 bulan $\geq 3$ kali suntik 


\begin{tabular}{|c|c|c|c|c|c|c|c|c|}
\hline \multirow{3}{*}{$\begin{array}{l}\mathbf{N} \\
\mathbf{o}\end{array}$} & \multirow[t]{3}{*}{ Haid } & \multicolumn{4}{|c|}{$\begin{array}{c}\text { Pengguna KB suntik } 3 \\
\text { bulan } \geq 3 \text { kali }\end{array}$} & \multirow{2}{*}{\multicolumn{2}{|c|}{ Jumlah }} & \multirow[t]{2}{*}{ Kemaknaan } \\
\hline & & \multicolumn{2}{|c|}{$\mathbf{Y a}$} & \multicolumn{2}{|c|}{ Tidak } & & & \\
\hline & & $\mathbf{n}$ & $\%$ & $\mathbf{n}$ & $\%$ & $\mathbf{n}$ & $\%$ & \\
\hline 1 & Tidak & 6 & 54,5 & 5 & 45,5 & 11 & 100 & $P$ value 0,016 \\
\hline \multirow[t]{2}{*}{2} & Ya & 18 & 94,7 & 1 & 5,3 & 19 & 100 & Bermakna \\
\hline & Jumlah & 24 & & 6 & & 30 & 100 & \\
\hline
\end{tabular}

Dari tabel diatas, dapat dilihat bahwa akseptor yang menggunakan $\mathrm{KB}$ suntik 3 bulan $\geq 3$ kali yang mengalami metroragia lebih besar $(94,7 \%)$ dibandingkan dengan akseptor yang tidak menggunakan KB suntik 3 bulan $\geq 3$ kali $(5,3 \%)$.

Hasil pengujian uji statistic dengan menggunakan Chi-Square menunjukan bahwa ada hubungan yang bermakna antara metroragia dengan akseptor $\mathrm{KB}$ suntik 3 bulan $\geq 3$ kali dimana $p$ value $=0,016$ lebih kecil dari $\alpha 0,05$ sehingga hipotesis yang menyatakan ada hubungan antara metroragia dengan akseptor kontrasepsi $\mathrm{KB}$ suntik 3 bulan terbukti.

\section{PEMBAHASAN}

Penelitian ini dilakukan pada 30 responden, dimana responden yang menggunakan $\mathrm{KB}$ suntik 3 bulan dibagi menjadi 2 kategori yaitu ya (ibu yang memakai KB suntik 3 bulan $\geq$ kali datang) dan tidak (ibu yang memakai KB suntik 3 bulan < 3 kali datang). Berdasarkan hasil univariat menunjukan responden yang memakai KB suntik 3 bulan $\geq 3$ kali lebih banyak $(80,0 \%)$ dibandingkan dengan respon yang memakai KB suntik 3 bulan $<3$ kali datang $(20,0 \%)$. Sehingga diketahui bahwa pengguna kontrasepsi KB suntik 3 bulan sekali $\geq 3$ kali datang lebih banyak dibandingkan yang $<3$ kali datang.

Hormon progesteron yang kuat mempengaruhi peningkatan berat badan sehingga merangsang hormon untuk meningkatkan nafsu makan yang ada di hipotalamus. Dengan adanya nafsu makan yang lebih banyak dari biasanya tubuh akan kelebihan zat-zat gizi. Kelebihan zatzat gizi oleh hormon progesterone diubah menjadi lemak dan di simpan di bawah kulit. Perubahan berat badan ini diakibatkan oleh penumpukan lemak yang berlebih hasil sintesa dari karbohidrat menjadi lemak. Pada umumnya penambahan berat badan bervariasi dari 2,3-2,9 $\mathrm{kg}$ dalam tahun pertama.(Suparyanto, 2010).

Pada penelitian ini, peningkatan berat badan dibagi menjadi 2 kategori yaitu naik dan tidak. Dari hasil analisis univariat sebagian besar dari 30 akseptor yang berat badannya naik yaitu
20 akseptor $(66,7 \%)$ sedangkan yang tidak naik berat badannya sebesar 10 akseptor $(33,3 \%)$

Dari hasil analisa bivariat dengan uji ChiSquare di dapat nilai $p$ value $=0,009$ lebih kecil dari $\alpha 0,05$. Maka ada hubungan yang bermakna antara peningkatan berat badan dengan penggunaan kontrasepsi KB suntik 3 bulan di Puskesmas Tanjung Raman Tahun 2019. Dengan demikian hipotesis yang menyatakan bahwa ada hubungan antara pemakaian KB suntik 3 bulan dengan peningkatan berat badan terbukti secara statistik.

Berdasarkan hasil penelitian Desi Ekawati (2010) mengatakan bahwa KB suntik 3 bulan (DMPA) mempengaruhi kenaikan berat badan akseptor dibandingkan yang tidak memakai $\mathrm{KB}$ suntik 3 bulan. Hasil penelitian Desi Ekawati (2010) sesuai dengan hasil penelitian saya yang menyatakan bahwa KB Suntik 3 bulan mempengaruhi peningkatan berat badan. Kenaikan berat badan pada akseptor KB suntik 3 bulan terjadi karena hormone progesterone merangsang nafsu makan ibu lebih besar dari biasanya sehingga tubuh akan kelebihan zat gizi dan akan diubah menjadi lemak sehingga ibu mengalami peningkatan berat badan.

Pada umumnya pengaruh KB suntik 3 bulan antara lain terjadinya perubahan pada pola haid, seperti tidak teratur, perdarahan bercak, mual, sakit kepala, nyeri payudara ringan,penambahan berat badan dan kemungkinan terlambatnya pemulihan kesuburan setelah penghentian pemakaian.(Sujiyatini, 2009)

Perubahan pada pola haid ini terjadi karena pengaruh hormon progesteron di mulai dari perdarahan bercak atau flek hingga perdarahan yang berkepanjangan, bahkan $70 \%$ pengguna $\mathrm{KB}$ suntik bisa tidak mens. Setiap individu memiliki respon yang berbeda-beda dalam penerimaan hormon ini (Haryanto, 2011).

Pada penelitian ini haid di bagi menjadi 2 kategori yaitu tidak metroragia dan metroragia. Dari hasil penelitian univariat 11 responden $(36,7 \%)$ yang tidak metroragia, sedangkan yang metroragia yaitu 19 responden $(63,3 \%)$.

Hasil analisa bivariat dengan uji ChiSquare didapat nila $p$ value $=0,016$ lebih kecil dari $\alpha=0,05$. Maka ada hubungan antara metroragia dengan penggunaan kontrasepsi $\mathrm{KB}$ suntik 3 bulan di Puskesmas Tanjung Raman Tahun 2019. Haid yang tidak teratur ini terjadi karena pengaruh hormon progesterone yang ada pada obat KB suntik 3 bulan. 


\section{KESIMPULAN}

Responden yang memakai KB suntik 3 bulan $\geq 3$ kali datang lebih besar dibandingkan dengan ibu yang memakai KB suntik 3 bulan $<3$ kali. Responden yang mengalami peningkatan berat badan lebih besar dibandingkan ibu yang tidak mengalami peningkatan berat badan. Responden yang mengalami metroragia lebih besar dibandingkan yang tidak mengalami metroragia. Ada hubungan yang bermakna antara pengguna $\mathrm{KB}$ suntik 3 bulan $\geq 3$ kali datang dan metroragia dengan peningkatan berat badan di Puskesmas Tanjung Raman Tahun 2019

\section{SARAN}

Bagi akseptor KB Suntik untuk menjaga berat badan agar tetap ideal dengan cara menjalani gaya hidup sehat, makan makanan yang bernutrisi seimbang, menghindari makanan tinggi gula dan tinggi lemak, olahraga secara rutin dan istirahat yang cukup. Bagi petugas kesehatan untuk lebih intens memberikan asuhan yang tepat terhadap keluhan dari akseptor dan memberikan konseling mengenai kontrasepsi yang tepat sesuai dengan kebutuhan pasien.

\section{DAFTAR PUSTAKA}

Adhiyasasti, Menur. 2018.Alasan Berat Badan Berubah Setelah Pakai Kontrasepsi Hormonal.

https://skata.info/article/detail/187/alasanberat-badan-berubah-setelah-pakaikontrasepsi-hormonal.

BKKBN.2014.Situasi dan Analisis Keluarga Berencana.InfoDATIN:Jakarta.

Haryanto.2010. Pengaruh Kb Suntik (http://www.klikdokter.com).

Kemenkes RI.2013.Situasi Keluarga Berencana. Buletin Jendela Data dan Informasi Kesehatan. Semester II: Jakarta.

Manuaba, Ida Ayu Chandranita, dkk.2010.Ilmu Kebidanan Penyakit Kandungan dan KB untuk Pendidikan Bidan.EGC:Jakarta.

Notoatmodjo, Soekidjo. 2010. Metodologi Penelitian Kesehatan. Jakarta : PT. Rineka Cipta.
Sujiyatini, 2009. Panduan Lengkap Pelayanan KB Terkini. Cetakan Ketiga, Jogjakarta : Nuha Medika.

Sulistyawati, Ari. 2011. Pelayanan Keluarga Berencana. Jakarta : Yayasan Salemba Medika.

Syafrudin, 2009. Kebidanan Komunitas. Cetakan Pertama, Jakarta : $\quad$ EGC 
